

\section{الدور التعبيري للون فى الأشكال المعدنية ثلاثية الأبعاد}

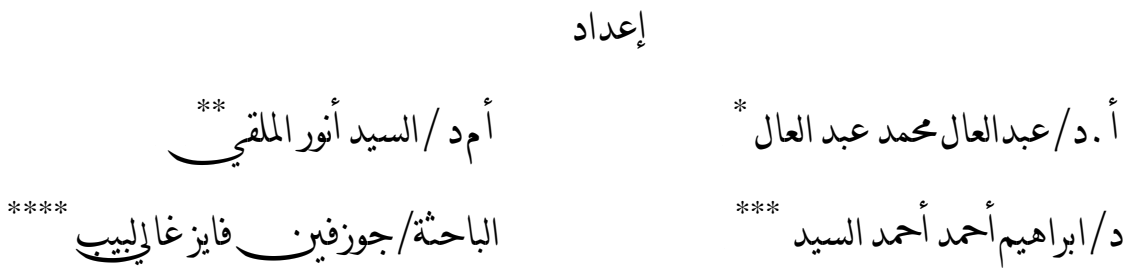

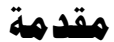

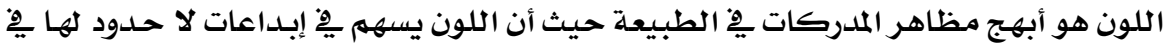

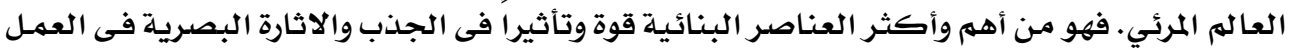

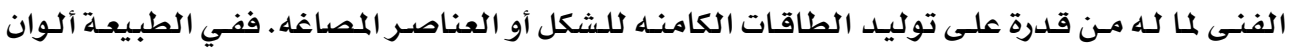

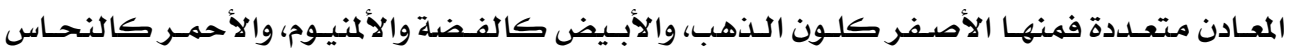

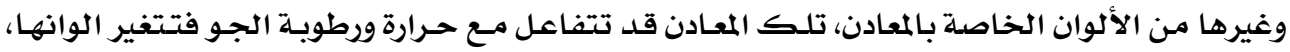

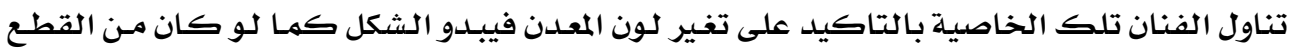

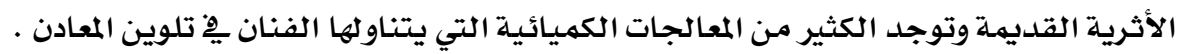

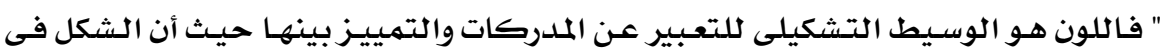

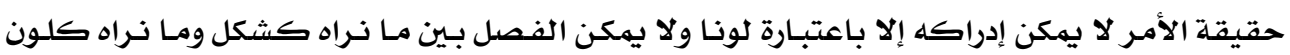

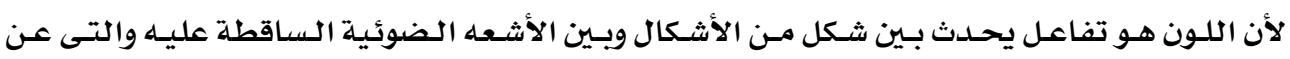

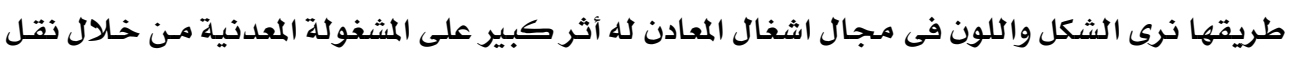

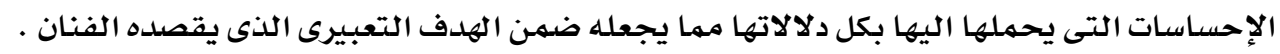

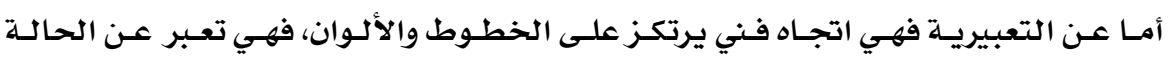

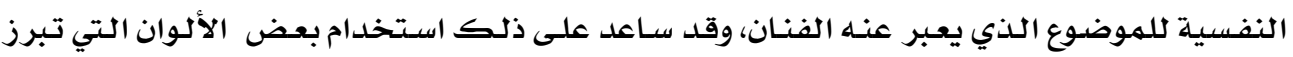

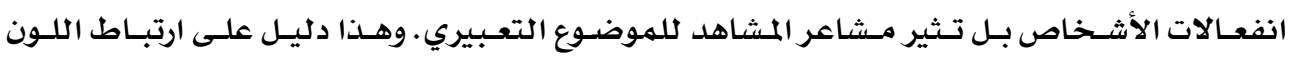
بالتعبير ارتباط وثيق.

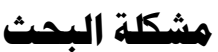
تأكيد فاعلية اللون كدور تعبيرى فى الأثكال ثلاثية الأبعاد.

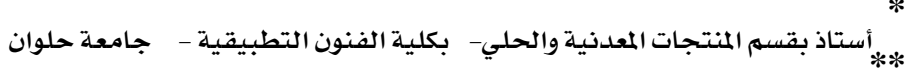

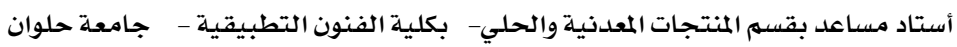

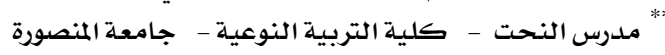

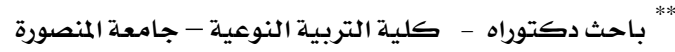




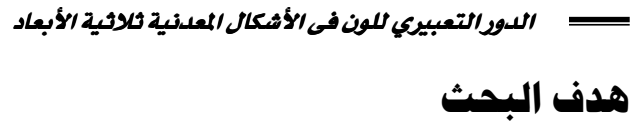

يهدف البحث إلى توضيح اهمية دور اللون كأساس تعبيرى .

اهمية البحث

تأكيد اللون كعنصـر للتعبير فى النحت المعاصـر والاستفادة مـن تجـارب الرواد في ايجـاد

صيخ تشكيلية لمجسمات معدنية ثلاثية الأبعاد .

فروض البحث :-

يفترض البحث إن :

اللون عنصر درامى تتأكد فاعليته فى المجسمات ثلاثية الأبعاد .

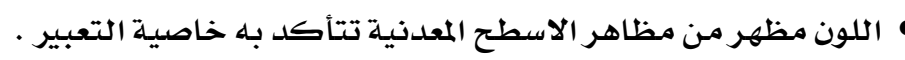

هدود البحث :- (1)

دراسة الدور التعبيرى للون كمنصر تشكيلى فى النحت المعاصر.

هن:هن البمث:-

استقرائي وصفي

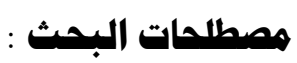

اللوز color:

اللون حس بصري يتوقف إدراكه على طول الموجات الضوئية المنبعثة مـن الجسه إلى العـين

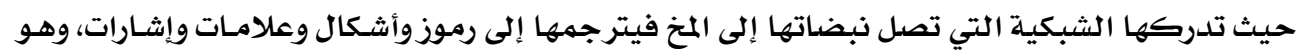

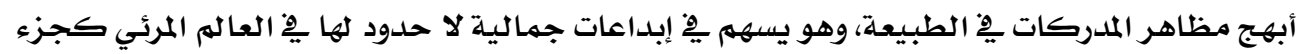

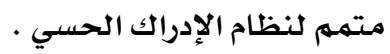

النحت المجسم (الثلاثي الأبعاد) Three-dimensional sculpture : الإدري •

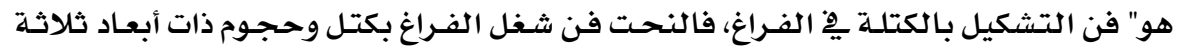

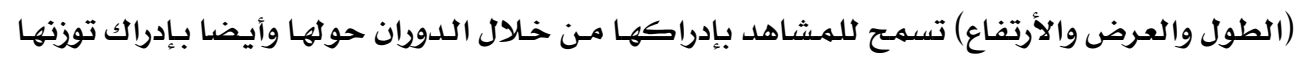

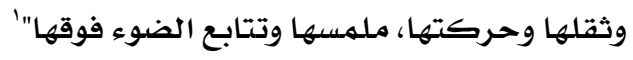

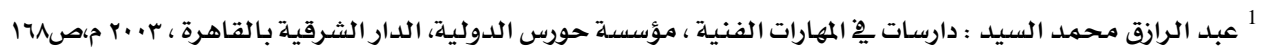


: Expressionism المدرسة التعبيرية

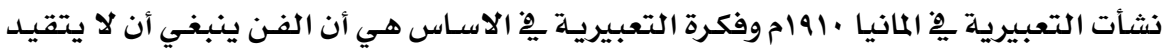

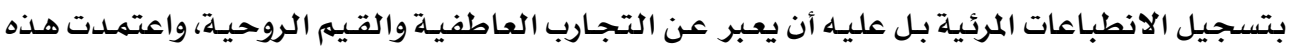

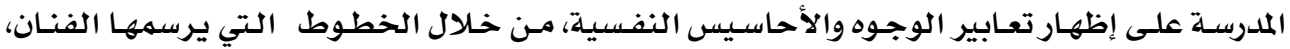

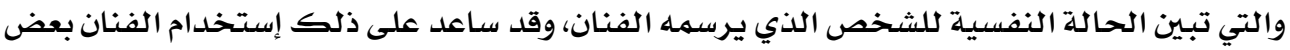

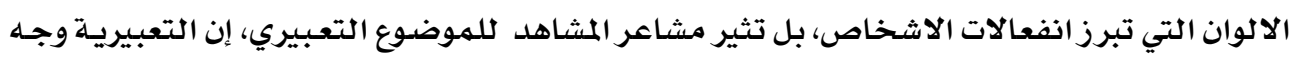

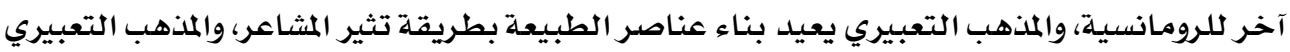

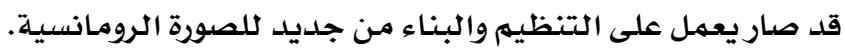
التعبيرية : قلد صياري

تيـار فنسى أخـذ بجـذوره فى التـاريخ ابتـداء مـن رسـوم الكهـوف البدائيـة وصـولا الى التعبيرات

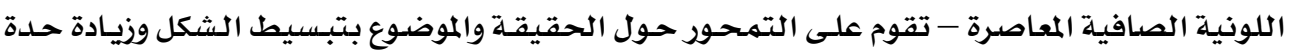

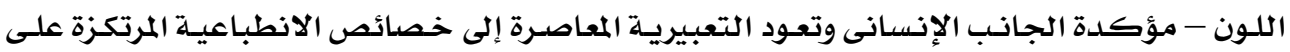

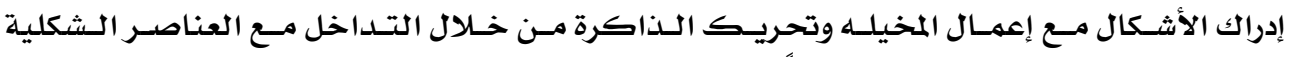

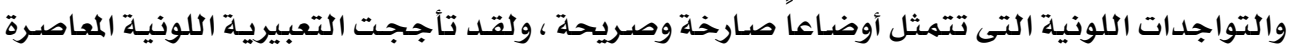

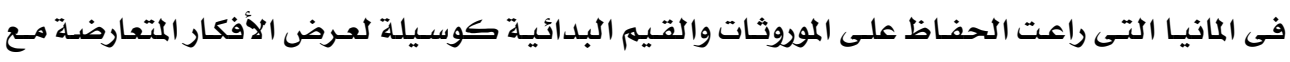

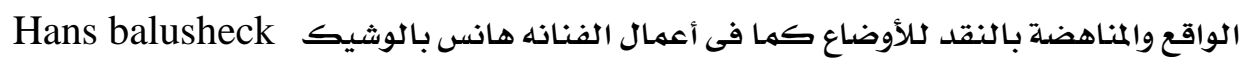

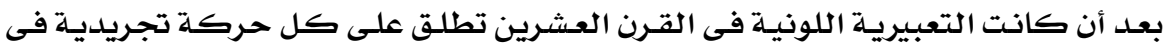

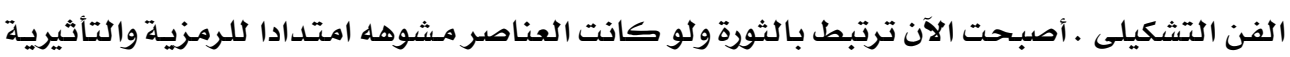

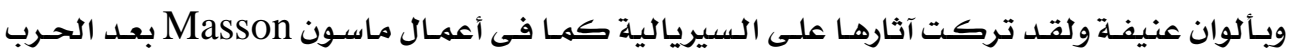
العالمية الثانية .

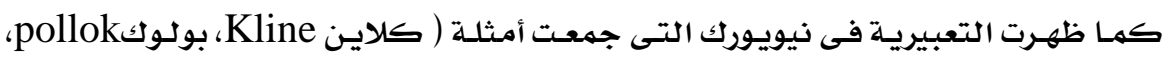

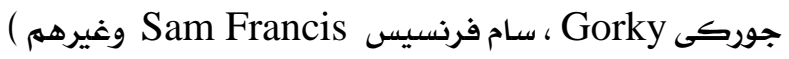

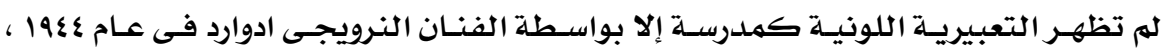

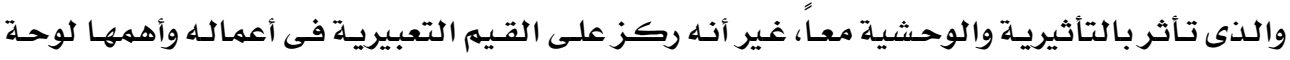

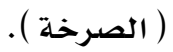

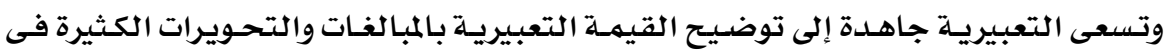

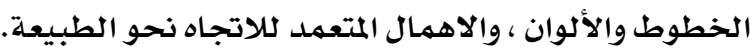

$$
\begin{aligned}
& \text { واهم الجماعات التى اتخذت التعبيرية متجها هى :- }
\end{aligned}
$$

The Bridge die bruke

blue rider 


\section{خصائص الملدرسة التعبيرية}

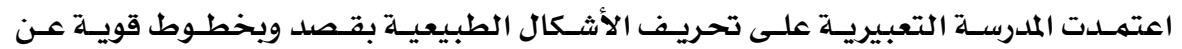

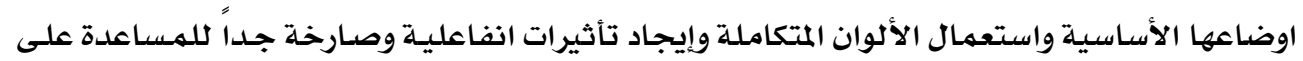

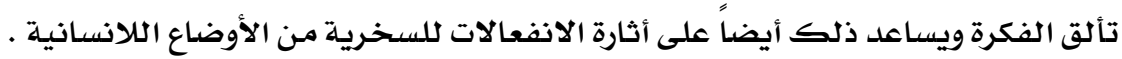

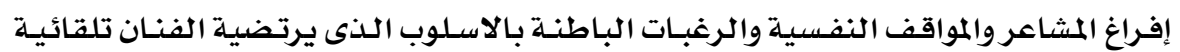

$$
\text { بعيداً عن التعاليهم وهى قريبـة من الفن الشعبى . }
$$

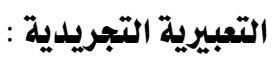

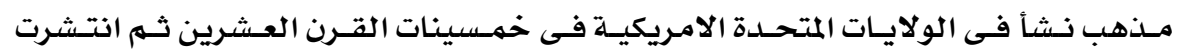

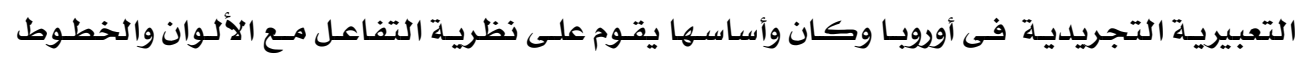

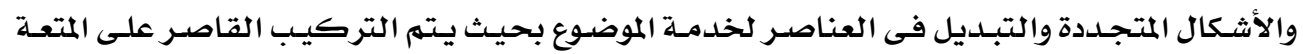

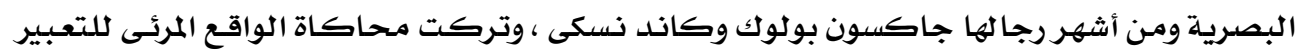

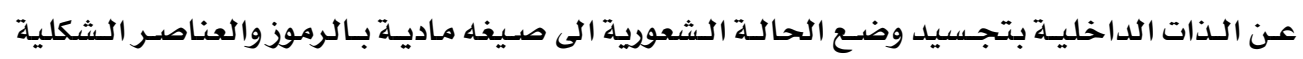

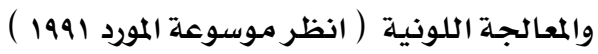

الثز والتعبير

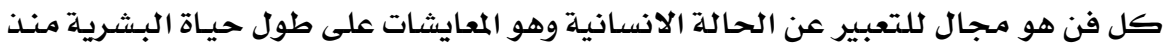

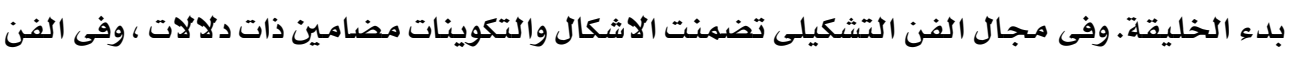

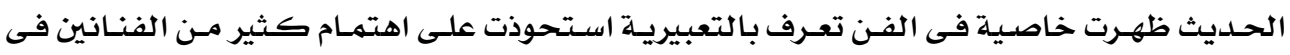

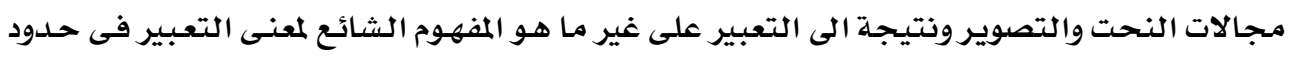

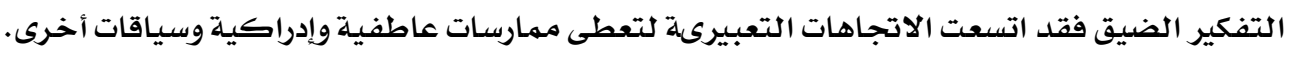

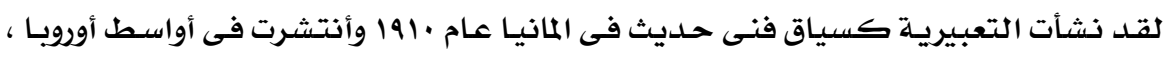

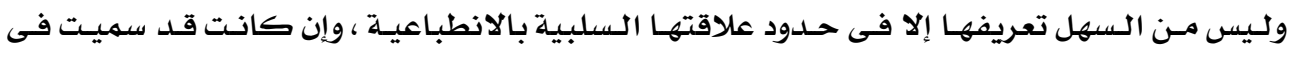

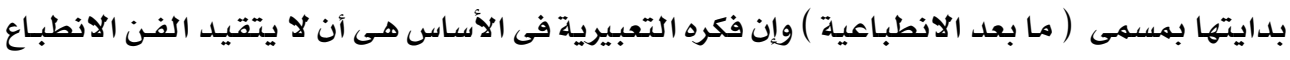

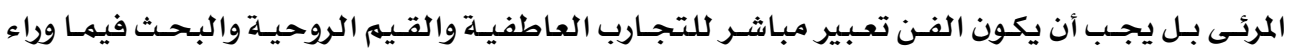

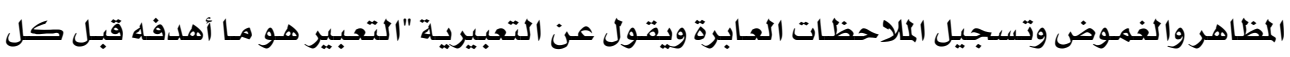

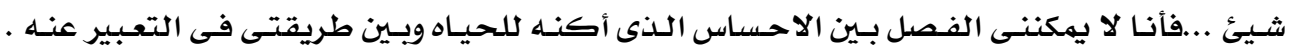

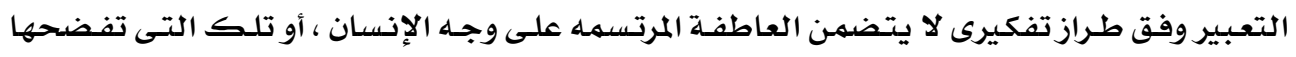

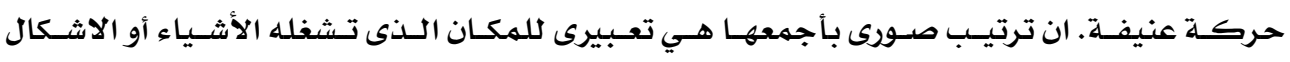


والمساحات الفارغـه حولها والنسبب ، كل يلعسب دوره. والتكوين هـو فن ترتيـب العناصـر المختلفـة ...

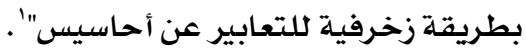
النحت التعبيري

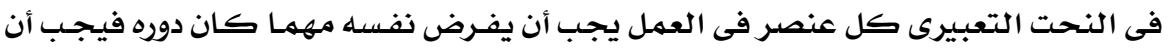

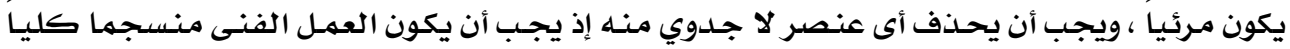

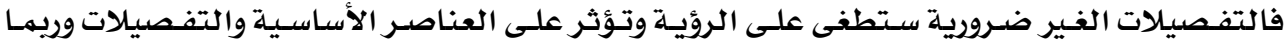

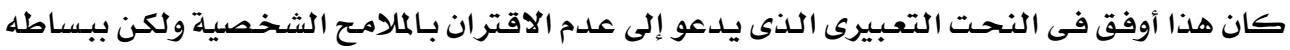

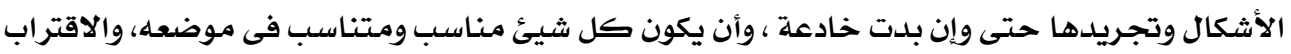

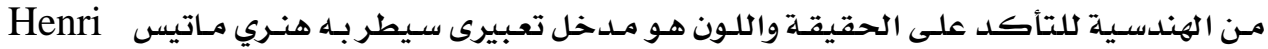

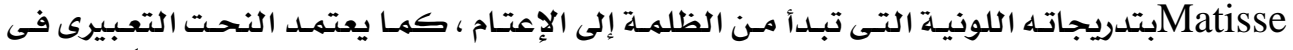

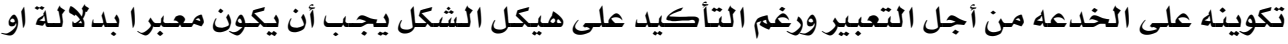

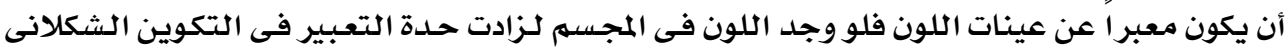

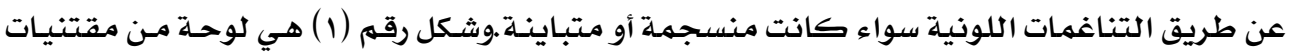

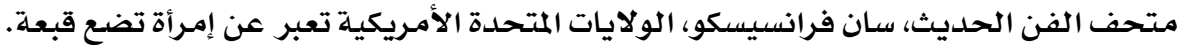

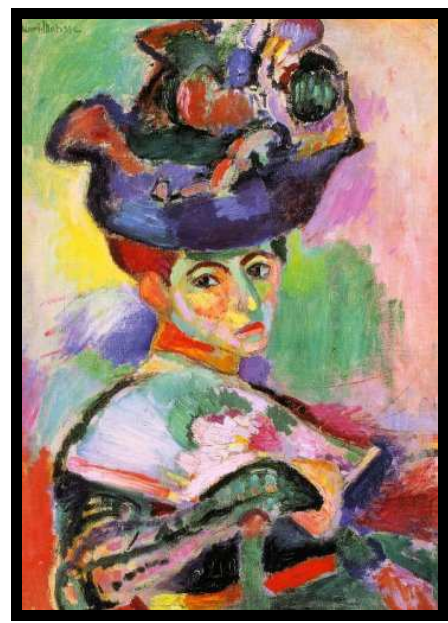

امرأة تضع قبعة

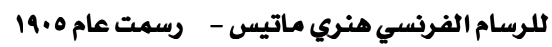

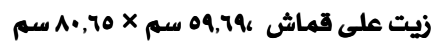

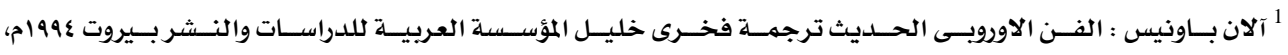




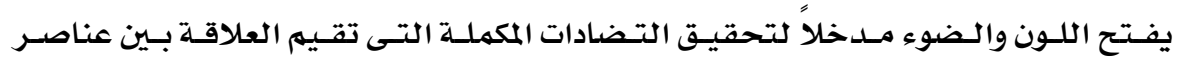

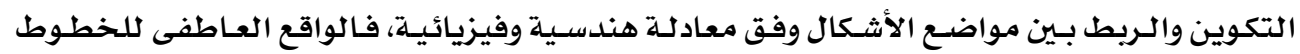

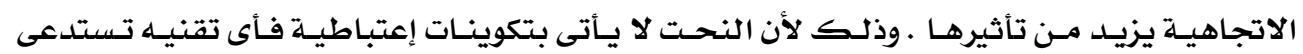

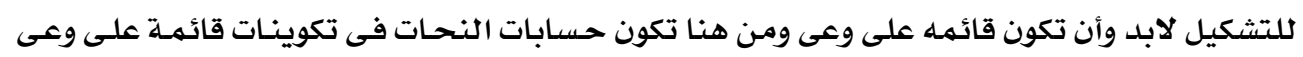

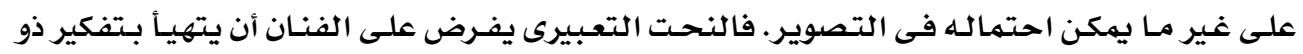

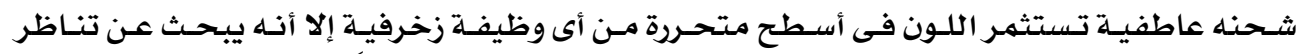

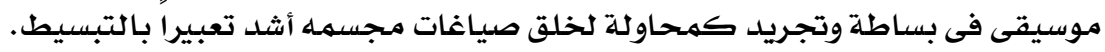

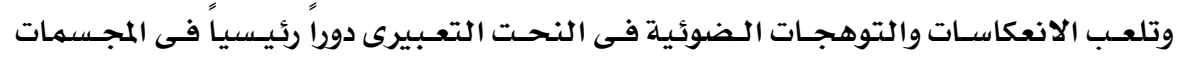

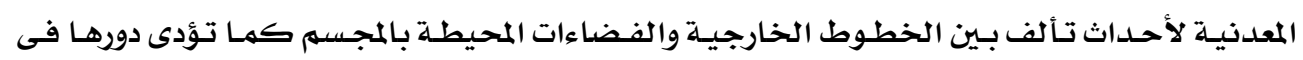

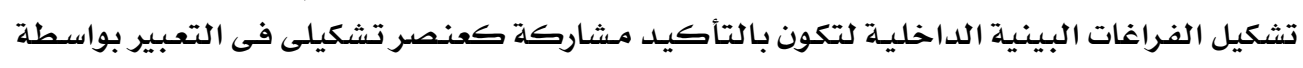

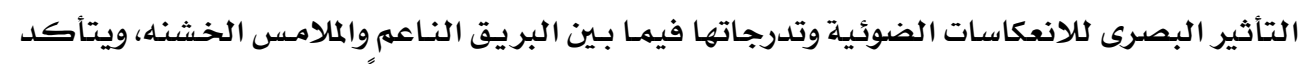

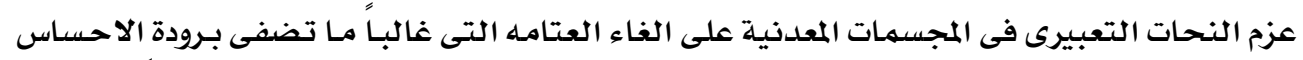

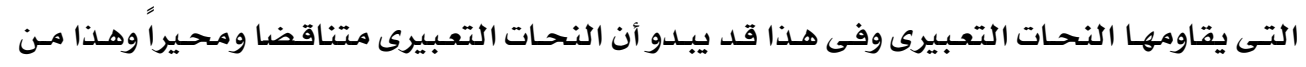

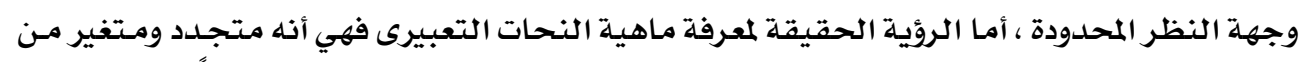

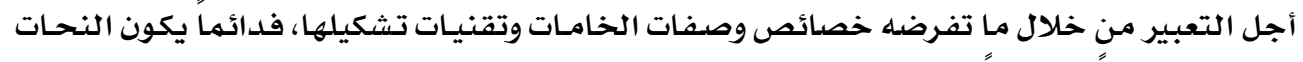

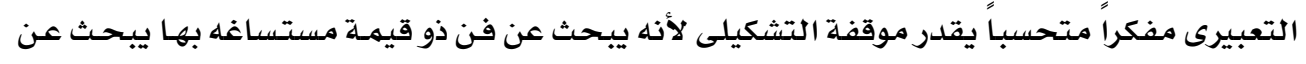

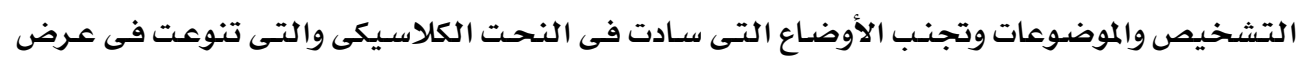

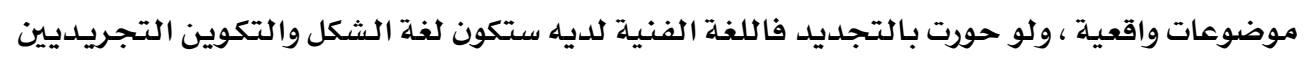

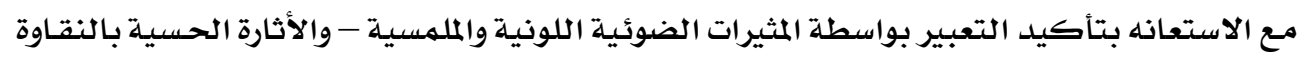

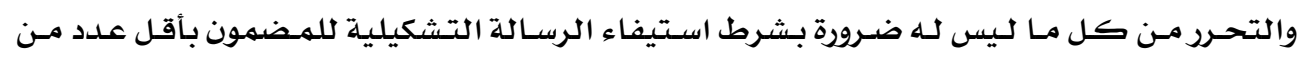
العناصر الثكلية .

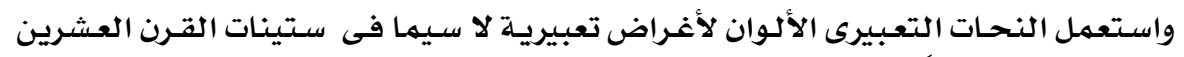

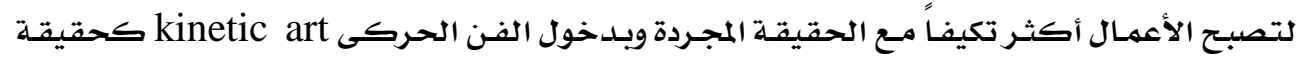

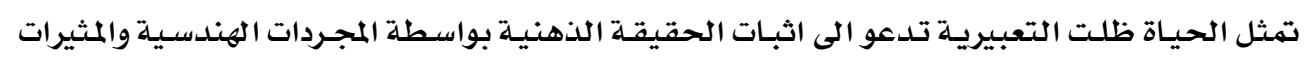

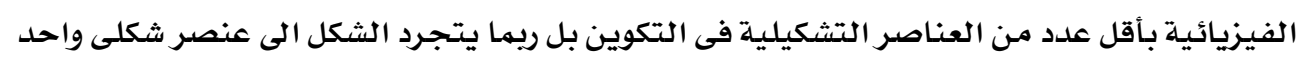

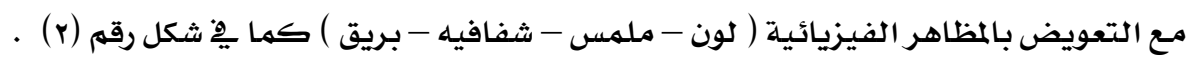




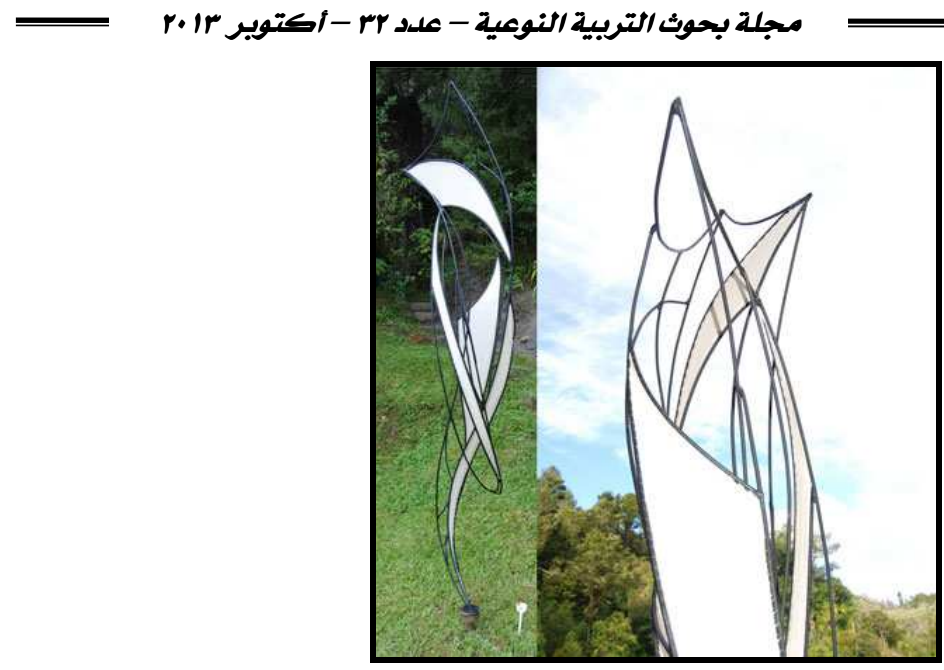

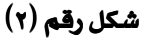

\section{Kinetic sculpture $^{1}$}
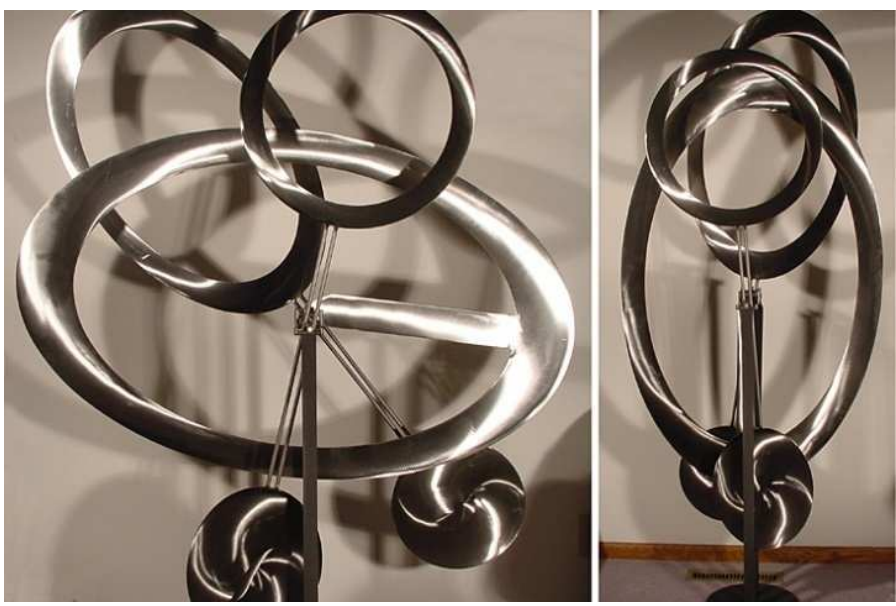

شكل رقم (r)

Kinetic sculpture ${ }^{2}$

${ }^{1}$ http://trishclarkevisual.blogspot.com/2011/09/blog-post.htmll

${ }^{2}$ http://www.cornermark.com/kinetic/images2/circleellipserelationship.jpg 


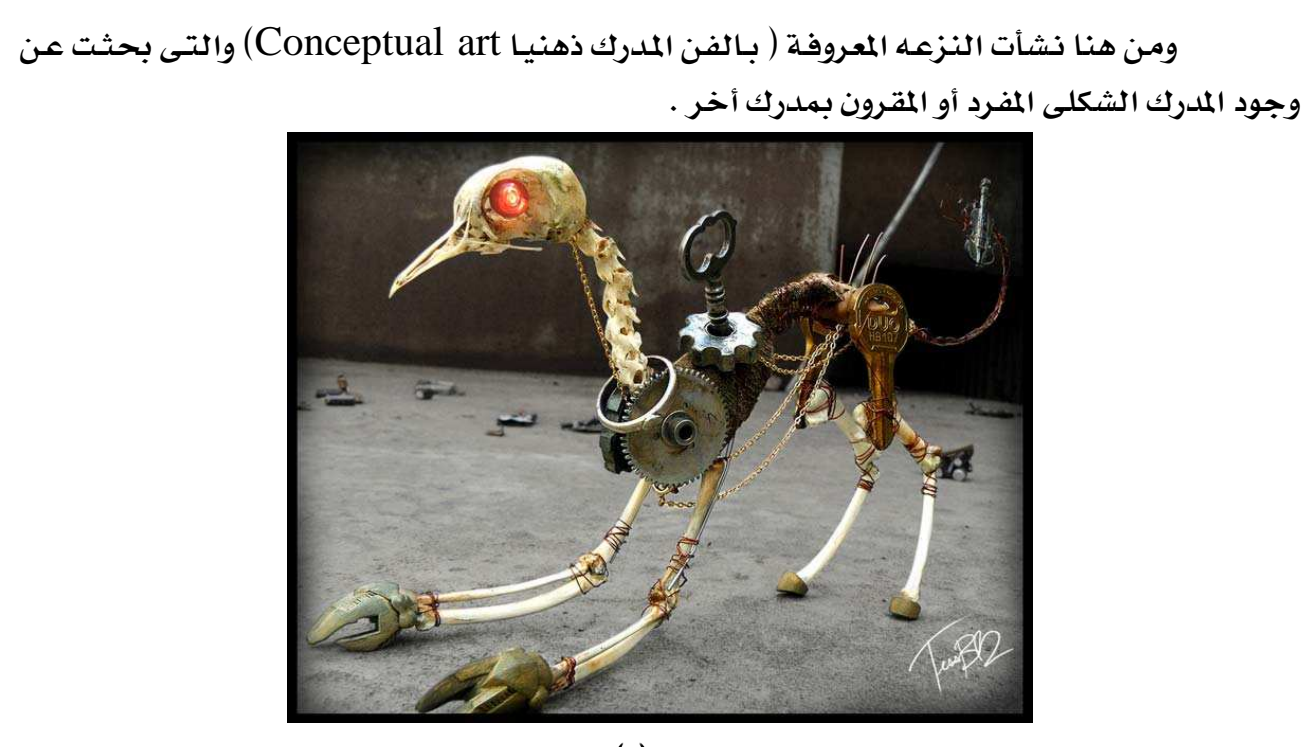

ثكل (๕)

Conceptual art

الفن المدرك ذهنيا

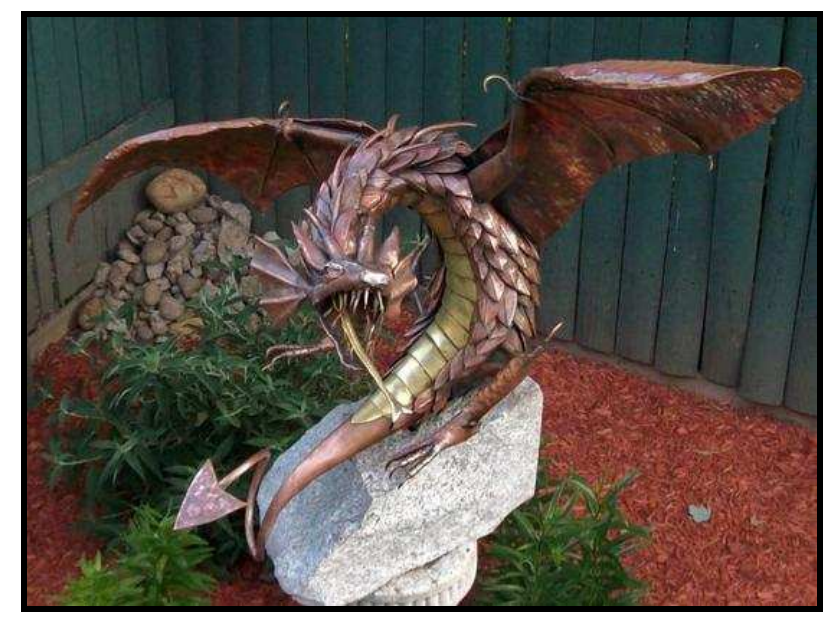

شكل رقم (0)

' Conceptual art

الفن المدرك ذهنيا

${ }^{1}$ http://www.greendiary.com/entry/recycled-metal-sculptures-from-rusty-metal-tometiculous-art/ 
وقد آثار أوغوست رودان Rodin Auguste وهو رائد النحت التعبيرى كيف ترك النحاتون

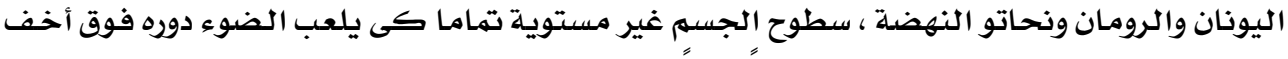

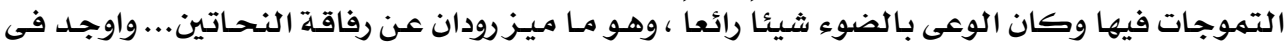

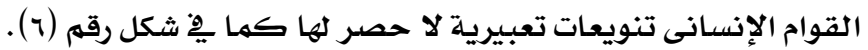

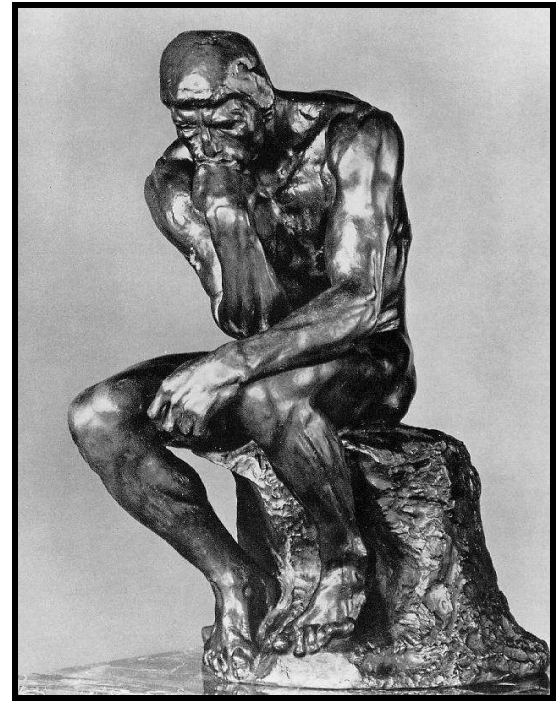

$$
\text { شكل رقم (؟) }
$$

\section{Rodin, Auguste-1880}

The Thinker -Bronze

68.6 × 89.4 x $50.8 \mathrm{~cm}$

وكان رودان يقصد تزويدنا باستعارات بصرية .. تتيح للناظر أن يفسرها كما يشاء .وبعـد

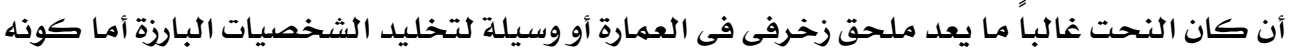

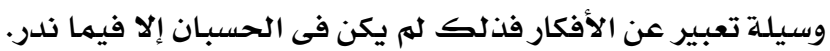

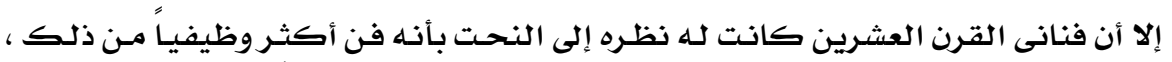

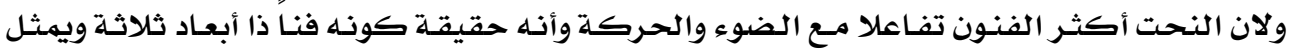

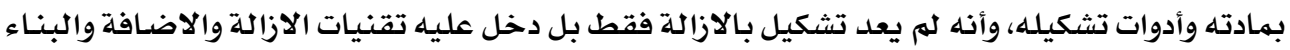

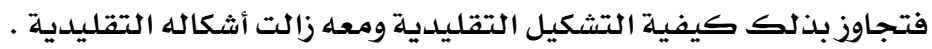


بابلو بيكاسو Picasso Pablo لقد عمل بيكاسو فى النحت فى عامه.919 ( رأس فتاه ) شكل رقم (v)، عالج فيها السطح البيضاوى بالتقطيع فى أوجه متعددة على طريقة التصوير التكعيبي

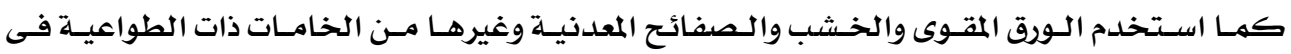

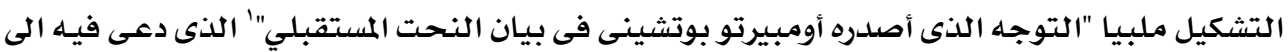

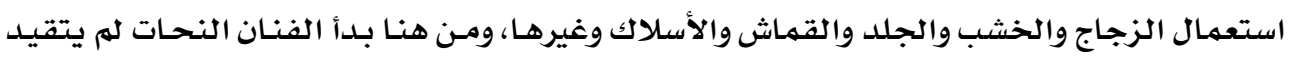

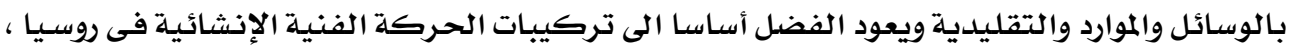

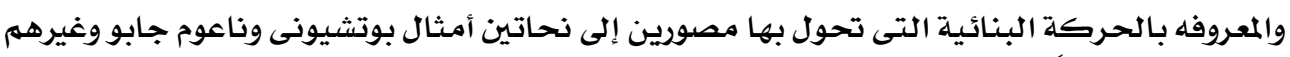

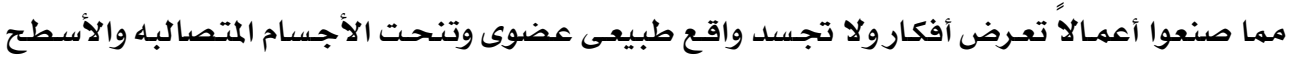

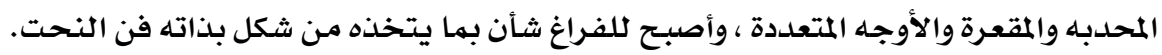

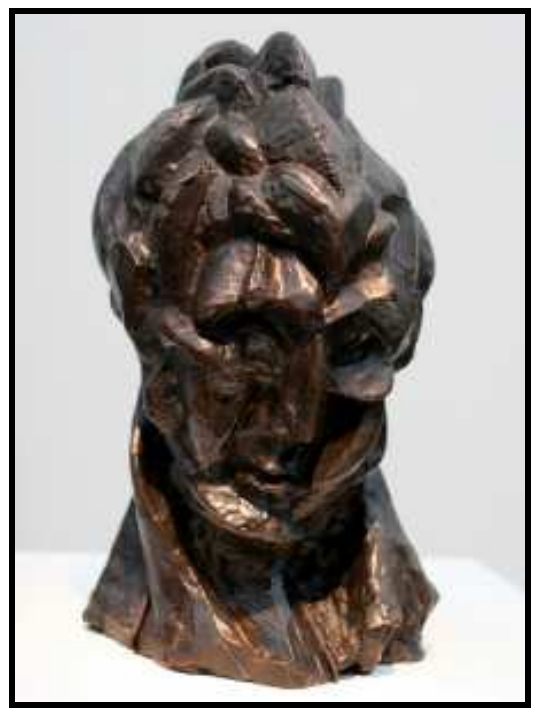

\section{شكل رقم (v)}

\section{rHead of a Woman}

\section{مدخل إلى النحت الحديث والمعاصر}

"اكتشف جاك ليجثـيتس Lipchitz Jacques أيضاً أنه بواسطة لى شـرائط رقيقة مـن

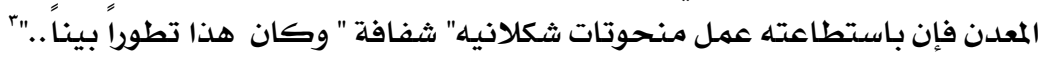

${ }^{1}{ }^{1}$ 2 http://pippiandme.wordpress.com/2012/03/04/picasso-at-the-national-gallery-of-nsw-sydney/

3 ${ }^{3}$ 


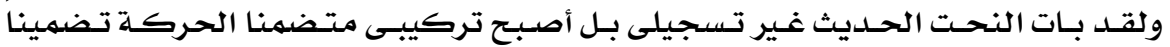

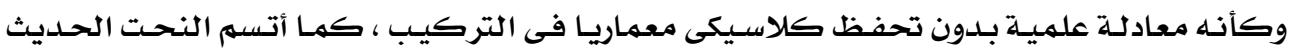

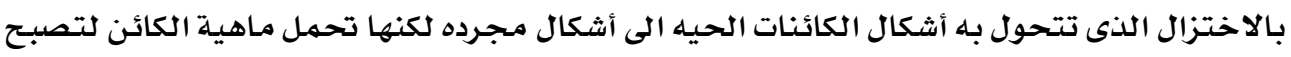

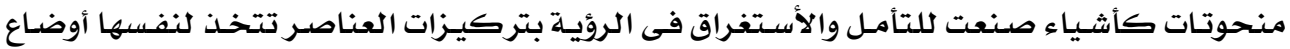
بؤرييه ينشأ عنها التعبير.

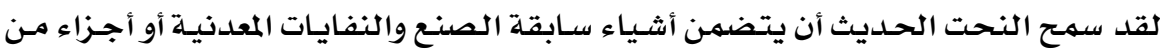

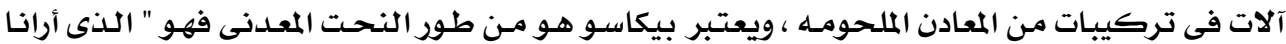

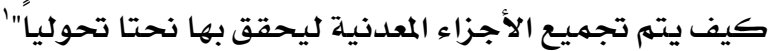

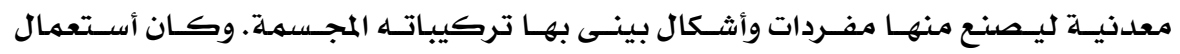

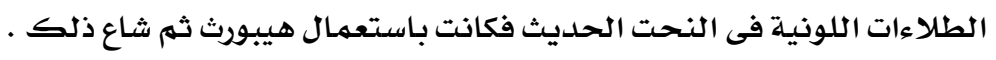

وكان استخدام المعدن الملحوم الذى استهله بيكاسو ثم الأميريكيان أمثال الكسندر كالدر

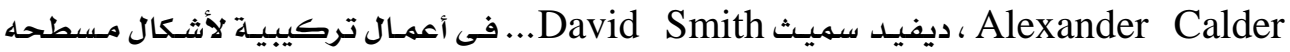

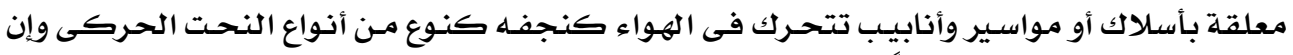

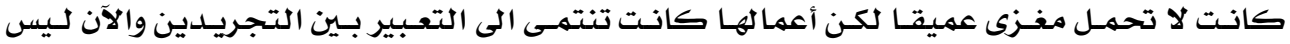

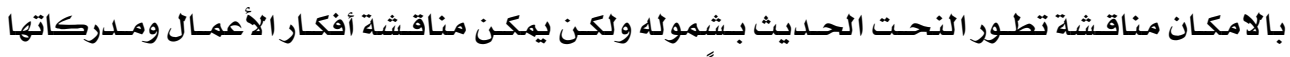

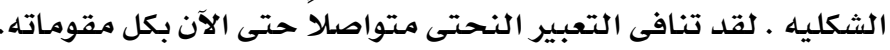

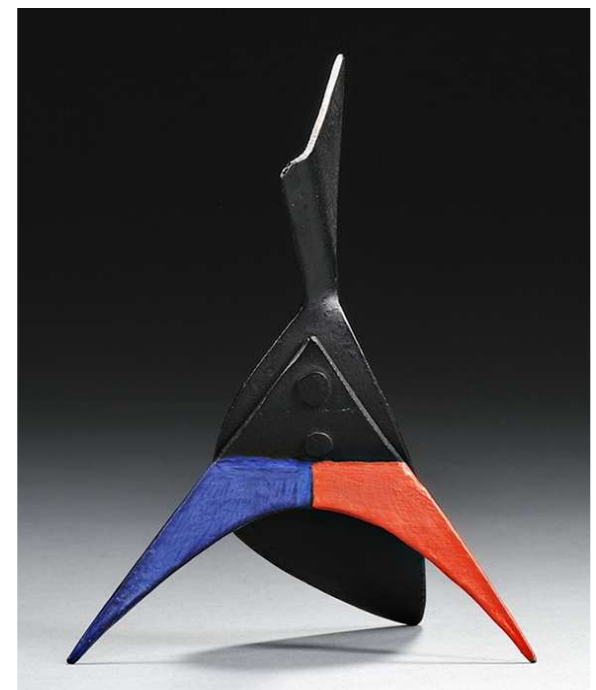

Alexander Calder Aكل رقم (A) الكسندر كالدر

(American, 1898-1976)

1 آلان باونيس : الفن الاوروبى الحديث ترجمة فخرى خليل المؤسسة العربية للدراسات والنشر بيروت ؟99ام، صاء؟r 


\section{البنية التكونية الاختزالية كأساس للتعبير فى النحت المعاصر}

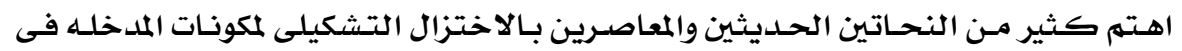

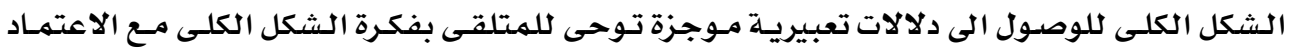

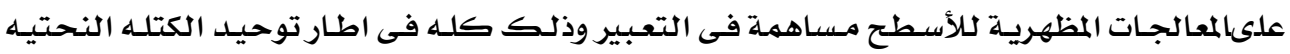

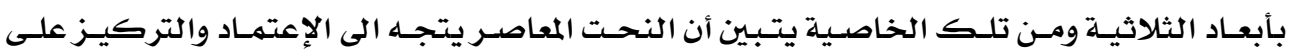

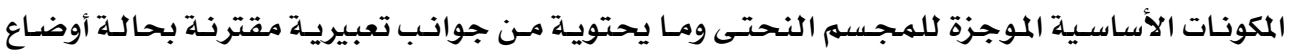

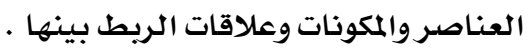

اللون والمعادن

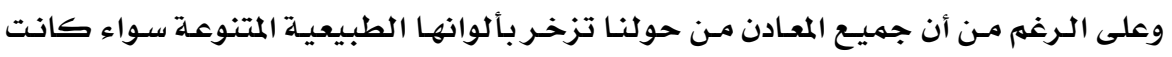

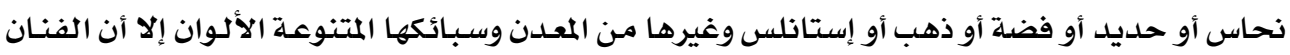

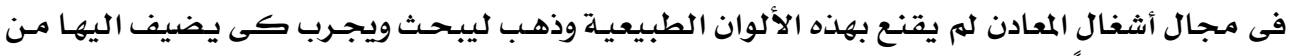

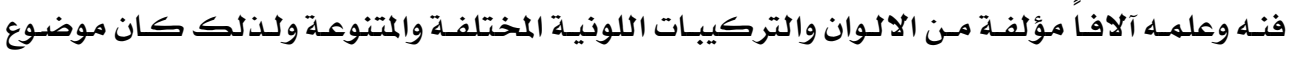

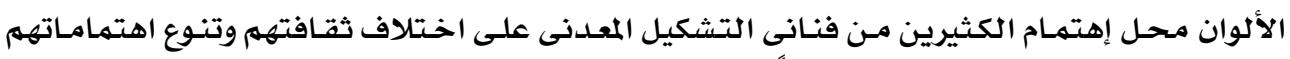

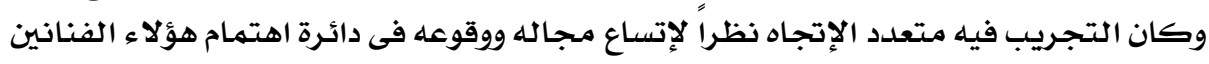

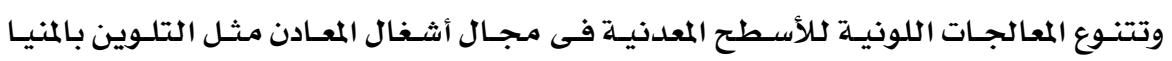

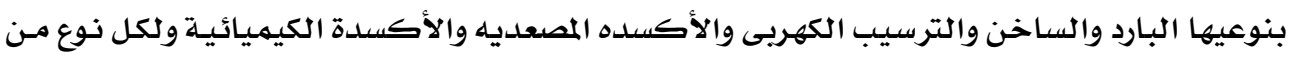

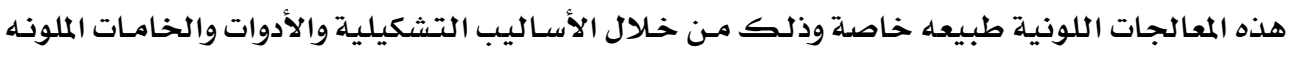

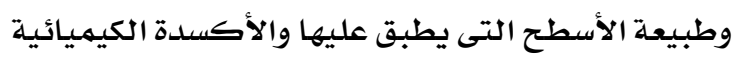

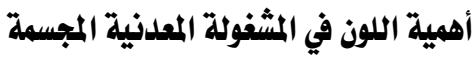

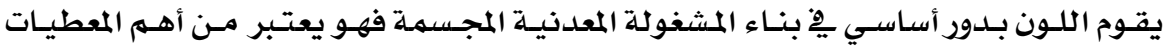

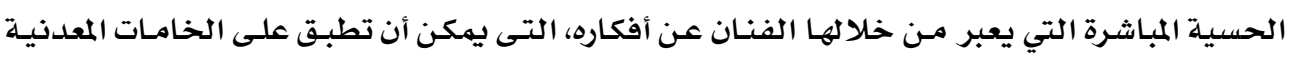

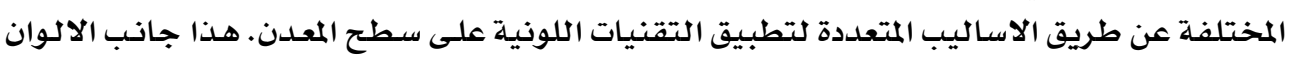

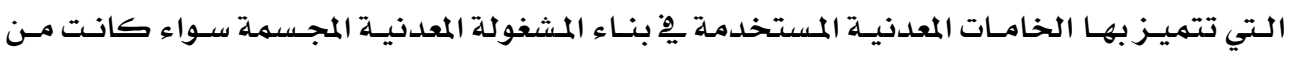

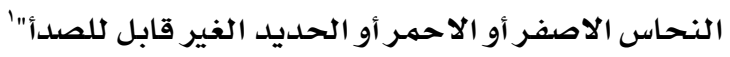

اللون عنصر مهمم من عناصر التعبير مِّْ مجال النحت المعاصر

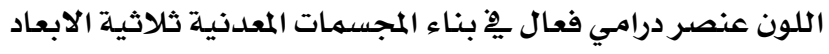
اللون مظهر من مظاهر الأسطح المعدنية

1 عبير محمد عفيفي : الأبعاد التشكيلية لتطبيق المينا على الاشكال المعدنية المجسمة، رسالة دكتوراه ، بحث غير منشور ،

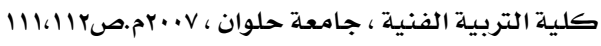




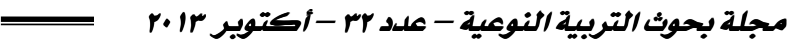

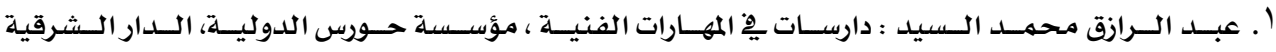

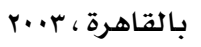

ץ. آلان باونيس : الفن الاوروبى الحديث ترجمة فخرى خليل المؤسسة العربية للدراسات والنشر بيروت ؟99 ام

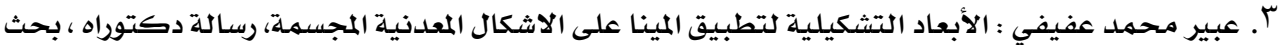

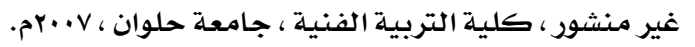

- http://trishclarkevisual.blogspot.com/2011/09/blog-post.htmll

- http://www.cornermark.com/kinetic/images2/circleellipserelationship.jpg

- http://www.greendiary.com/entry/recycled-metal-sculptures-from-rusty-metal-tometiculous-art/

- http://pippiandme.wordpress.com/2012/03/04/picasso-at-the-national-gallery-of-nswsydney/ 